\title{
Classic Imaging Findings of Tetralogy of Fallot with 64-slice Multidetector Computed Tomography
}

\author{
Nawshin Siraj, ${ }^{1}$ Nusrat Ghafoor, ${ }^{2}$ Md. Rokonujjaman Selim, ${ }^{3}$ S M Shaheedul Islam, ${ }^{4}$ Khalada Parvin Deepa, ${ }^{5}$ Mir Mahin Ashraf ${ }^{6}$
}

\begin{abstract}
Background \& objective: The present study was intended to demonstrate the role of Multidetector Computed Tomography (MDCT) in defining the extracardiac vascular abnormalities including the pulmonary arterial tree, Major Aortopulmonary Collateral Arteries (MAPCAs), patent ductus arteriosus (PDA), and detection of the common and uncommon findings in Fallot's Tetralogy cases for proper pre-surgical evaluation.

Methods: A retrospective review of all multidetector CT images acquired to evaluate suspected cases of Tetralogy of Fallot, presented at Ibrahim Cardiac Hospital \& Research Institute between July 2017 and July 2018, was done. This comprised of a total of 35 cases who were examined by 64-slice MDCT. The patients were divided into four main groups: those with classic Tetralogy of Fallot with no associations, those with common associations, those with uncommon associations and those with a combination of common and uncommon associations.

Results: In the present study, majority of the patients had levocardia (93.6\%), situs solitus (96.9\%) with none of the patients having either atrio-ventricular or arterio-ventricular discordance. Major findings of the patients were VSD (93.8\%), right ventricular outflow tract obstruction (65\%) with ventricular hypertrophy (75\%). All patients had overriding of aorta with over $60 \%$ of the patients having $50 \%$ and $28 \%>50 \%$ overriding. Approximately $3.1 \%$ of the patients had MPA atresia. MPA stenosis was detected in $93.3 \%$ of the cases.

Conclusion: A customized approach to MDCT imaging improves the diagnostic accuracy and reduces unnecessary prolongation of the study and sedation times. A careful preoperative perception of the complex cardiovascular anatomy in patients with Tetralogy of Fallot aids in exposing the patients to a directed and prepared surgical approach.
\end{abstract}

Key words: Tetralogy of Fallot, 64-slice multidetector computed tomography (64-MDCT), Image findings etc.

\section{INTRODUCTION:}

The Tetralogy of Fallot is a common congenital anomaly causing cardiac morbidity and mortality in pediatric population. It was first described by Louis Arthur Etienne Fallot in 1888 as "La Maladie Bleue". ${ }^{1}$ It is a clinical condition formed by a group of anatomical malformations of heart and its great vessels with fundamental features consisting of ventricular septal defect, biventricular connection of the aortic root, overriding of the muscular ventricular septum, obstruction to the right ventricular outflow tract, and right ventricular hypertrophy. ${ }^{2}$ The incidence of these malformations occur in 3 of every 10,000 live births, and accounts for $7-11 \%$ of all congenital heart diseases (CHDs). ${ }^{3,4}$ Common associations of Fallot's Tetralogy are pulmonary artery atresia (varying from mild hypoplasia to complete

\section{Authors' information:}

'Dr. Nawshin Siraj, Associate Professor \& Senior Consultant \& Head of the Department of Radiology \& Imaging, ICHRI, Dhaka

${ }^{2}$ Dr. Nusrat Ghafoor, Associate Professor \& Consultant, Department of Radiology \& Imaging, Ibrahim Cardiac Hospital \& Research Institute, Dhaka

${ }^{3}$ Dr. Md. Rokonujjaman Selim, Associate Professor \& Consultant, Department of Cardiac Surgery, Ibrahim Cardiac Hospital \& Research Institute, Dhaka

${ }^{4}$ Dr. S M Shaheedul Islam, Associate Professor \& Consultant, Department of Cardiology, Ibrahim Cardiac Hospital \& Research Institute, Dhaka

${ }^{5}$ Dr. Khalada Parvin Deepa, Specialist, Department of Radiology \& Imaging, Ibrahim Cardiac Hospital \& Research Institute, Dhaka

${ }^{6}$ Dr. Mir Mahin Ashraf, Medical Officer, Department of Radiology \& Imaging, Ibrahim Cardiac Hospital \& Research Institute, Dhaka 
absence of the main pulmonary artery or the non-confluence of its branches), right-sided aortic arch $(25 \%)$, atrial septal defect (ASD) (10\%) (so called Pentalogy of Fallot) and coronary artery abnormalities (10\%). Other less common associations include persistent left superior vena cava (SVC) and aberrant right subclavian artery. Rarely, tracheoesophageal fistula, rib anomalies, and scoliosis may be encountered.5,6,7 The manifestations and management of the disease are dependent on the severity of each component as well as age of the patients at which corrections are made. Presently, surgical correction is performed by closure of the VSD and relief of right ventricular outflow obstruction when patients are young. $7,8,9$ So, in order to plan an effective management of the disease, the surgeon needs the best perception of the malformation.

Congenital heart disease can be diagnosed by different imaging modalities. Echocardiography with Doppler performs well in defining intracardiac anomalies and estimating hemodynamics. However, it is limited by a small field of view, a variable acoustic window, inability to penetrate air and bone, difficulty in well-delineating extracardiac vascular structures. ${ }^{10}$ Cardiac angiography, although an invasive modality, it illustrates significant hemodynamic data and invariably demonstrates the accessible vascular anatomy. However, its ability to diagnose venous connections and arterial anatomy distal to high-grade stenosis or atresia is limited. It also uses high doses of ionizing radiation and is limited by the risks attributed to iodinated contrast material. ${ }^{10}$ Magnetic resonance (MR) imaging and MDCT are valuable noninvasive options. They are useful in demonstrating the complex cardiovascular morphology of Fallot's Tetralogy, especially the extracardiac associations as well as the pulmonary artery anatomy \& aortopulmonary collateral vessels. ${ }^{10}$ The development of 64-section MDCT, with its high scanning speed, superior spatial resolution, and improved capabilities for concurrent assessment of cardiovascular structures \& lung parenchyma, has demonstrated its improved application for evaluation of patients with CHD even in small infants. ${ }^{11}$ When combined with electrocardiographic (ECG) gating, CT images perfectly define the moving cardiac and extracardiac structures and permits evaluation of associated coronary artery anomalies. ${ }^{12,13}$ Multiplanar reformation is easily obtainable with the new advanced software thus reducing the prior disadvantage of $\mathrm{CT}$ image acquisition being solely in the transaxial plane. ${ }^{10}$

The purpose of this study was to demonstrate the role of MDCT in defining the extracardiac vascular abnormalities including the pulmonary arterial tree, MAPCAs, and patent ductus arteriosus (PDA), and also the detection of the common and uncommon findings in Fallot Tetralogy cases for proper pre-surgical evaluation.

\section{METHODS:}

Having obtained an ethical clearance from the Ibrahim Cardiac Hospital \& Research Institute, we retrospectively reviewed all multidetector CT images acquired to evaluate suspected cases of Tetralogy of Fallot referred by the physicians of the same or different Institutes/Hospitals between July 2017 and July 2018. This comprised of a total of 35 cases who were examined by MDCT. Of them 3 cases were excluded from the study, as they were not diagnosed as Tetralogy of Fallot by MDCT imaging and the preliminary clinical diagnosis was proven to be wrong. The patient population consisted of 23 males and 9 female patients with a mean age of $6 \pm 4$ (range: $1-14$ ) years. CT scans were obtained with a 128 slice-MDCT scanner (GE Revolution EVO). The patients were divided into four main groups: those with classic Tetralogy of Fallot with no associations, those with common associations, those with uncommon associations and those with a combination of common and uncommon associations.

\section{MDCT Imaging protocol:}

Data acquisition was performed in a craniocaudal direction from the level of the thoracic inlet down to the diaphragm. The scanning parameters include 64-0.6 mm detector collimation, 64-0.6 $\mathrm{mm}$ section collimation with a z-flying focal point, 
330 ms gantry rotation time, 0.9 pitch and 120 $k V p$ tube potential. Contrast enhancement was achieved by non-ionic contrast agent (Iohexol 350 [Omnipaque], Cork, Ireland) calculated according to the patient weight, with a maximum dose of 2 $\mathrm{ml} / \mathrm{kg}$, injected at $1.2-2 \mathrm{ml} / \mathrm{s}$, pressure $80-100$ through an 22-gauge canula into peripheral vein. The initiation of scanning was triggered by locating the ascending aorta with a density of 100 $\mathrm{H}$. Images are restored with the least moving objects and then moved for storage to a workstation (ADW GE Health Care).

\section{Image analysis:}

The axial image examination was the most important step in image analysis, with the vessels being carefully traced even if it was so fragile. Multiplanar reformations were used in the analysis as a confirmatory method. The data set was then selected as representing the optimum setting of the reconstruction window with the least motion objects. The selected images were displayed using two techniques of visualization, multiplanar reformation and 3D reconstruction made by volume. To obtain accurate measurements, multiplanar reformation was individually adjusted to the long axis of the structure of interest. Volume rendering was the longest post-processing procedure, but it helped to envision complex anatomy in 3D. Imaging data analyses were carried out by one researcher with six years of experience in MDCT imaging in congenital heart disease, supervised by a second investigator with ten years of MDCT imaging experience. The two investigators were unaware of the research study being contemplated.

\section{Calculations:}

Measurements were taken from the infundibulum, pulmonary arteries, the total transverse diameter of the main pulmonary spine, the right main and left main pulmonary arteries in the axial images in their widest form. The diameters of the descending aorta were determined on axial images at the level of the diaphragm crus. For patients with proof of pulmonary hypoplasia, the CT McGoon ratio was determined using the following formula ${ }^{14}: X=L P A+R P A / D A o$ where, $X$ stands for McGoon ratio, LPA = left pulmonary artery, RPA $=$ right pulmonary artery and DAo = descending aorta at the level of the diaphragmatic crus. The cut-off value of the McGoon ratio is 1.7, below which a rather small caliber central pulmonary artery indicates that may warrant faster surgical shunts. In the study, the diameters of major aortopulmonary collateral (MAPCAs) and patent ductus arteriosus (PDA) were also calculated.

\section{Statistical analysis:}

Data were analyzed using SPSS (Statistical Package for Social Sciences). Descriptive statistics were used to analyze the data. Results were expressed as frequency with corresponding percentage for categorical data and as medean and standard deviation from the mean for continuous data.

\section{RESULTS:}

The median age of the patients was 6 years with youngest and the oldest patients being 1 and 14 years respectively. Approximately $72 \%$ of the patients were male with male to female ratio being roughly 7:3 (Table I). Majority (93.6\%) of the patients had levocardia (Table II). Of the total patients, 31(96.9\%) had situs solitus and only $1(3.1 \%)$ patient had situs inversus. None of the patients had either atrio-ventricular or arterio-ventricular discordance. Thirty (93.8\%) patients had ventricular septal defect (VSD). Approximately $85 \%$ of the patients had right ventricular outflow tract obstruction leading to ventricular hypertrophy (75\%). All patients had overriding of aorta. Over $60 \%$ of the patients had $50 \%$ and $28 \%>50 \%$ overriding of aorta (Table III). Thirty one $(96.9 \%)$ patients had main pulmonary artery (MPA) stenosis and $3.1 \%$ patients had main pulmonary artery (MPA) atresia. While MPA stenosis was detected in $96.9 \%$ of the cases, RPA and LPA stenoses were found in 50 and $59.4 \%$ of the cases respectively. MPA, RPA and LPA were confluent in almost all cases $(96.9 \%)$. Angle between MPA and LPA were acute $(53.1 \%)$ and obtuse $(46.9 \%)$. In majority $(87.5 \%)$ of the cases McGoon ratio was reduced, 
with more than two-thirds being significantly reduced $(68.8 \%)$ (Table IV). In terms of common associated anomalies, 30(93.3\%) patients had major aorto-pulmonary collaterals and IVC (Inferior Vena Cava) draining into the RA (right atrium), and 29(90.6\%) patients had left-sided aortic arch and $3(9.4 \%)$ patients had right-sided aortic arch (Table $\mathrm{V}$ ). Other less common associated anomalies were PDA $(9.4 \%)$, ASD $(12.5 \%)$, aberrant left subclavian artery $(9.4 \%)$ and coronary artery anomalies (12.5\%) (Table VI).

\begin{tabular}{|c|c|c|c|}
\hline $\begin{array}{l}\text { Demographic } \\
\text { variables }\end{array}$ & Frequency & Percentage & $\begin{array}{c}\text { Mean } \pm \text { SD } \\
\quad \text { (range) }\end{array}$ \\
\hline Age (years) & -- & -- & $6.0 \pm 4(1-14)$ \\
\hline \multicolumn{4}{|l|}{ Sex } \\
\hline Male & 23 & 71.9 & -- \\
\hline Female & 9 & 28.1 & -- \\
\hline
\end{tabular}

Table II. Distribution of patients by their cardiac position $(n=32)$

\begin{tabular}{lcc}
\hline Cardiac position & Frequency & Percentage \\
Levocardia & 30 & 93.8 \\
Dextrocardia & 2 & 6.2
\end{tabular}

Table III. Distribution of children by common image findings of TOF

$\begin{array}{lcc}\text { Classic TOFs } & \text { Frequency } & \text { Percentage } \\ \text { Cardiac situs } & & \\ \quad \text { Situs solitus } & 31 & 96.9 \\ \quad \text { Situs Inversus } & 1 & 3.1 \\ \text { Atrio-ventricular connection } & & \\ \quad \text { Concordance } & 32 & 100.0 \\ \text { Ventriculo-arterial connection } & & \\ \quad \text { Concordance } & 32 & 100.0 \\ \text { VSD } & 30 & 93.8 \\ \text { Right ventricular outflow tract obstruction } & 27 & 84.4 \\ \text { Right ventricular hypertrophy } & & \\ \quad \text { Mild } & 12 & 37.5 \\ \text { Moderate } & 12 & 37.5 \\ \quad \text { Not hypertrophied } & 3 & 9.4 \\ \text { Overriding of aorta } & & \\ 50 \% & 20 & 62.5 \\ >50 \% & 9 & 28.1 \\ \quad<50 \% & 3 & 9.4 \\ \text { Double outlet right ventricle } & 32 & 100.0\end{array}$

Table IV. Distribution of patients by pulmonary arteries and its types $(n=32)$

$\begin{array}{lcc}\text { Pulmonary artery } & \text { Frequency } & \text { Percentage } \\ \text { anomalies and its types } & 1 & 3.1 \\ \text { MPA Atresia } & 28 & 96.9 \\ \text { MPA Stenosis }(\mathrm{n}=31) & 16 & 50.0 \\ \text { RPA Stenosis } & 19 & 59.4 \\ \text { LPA Stenosis } & & \\ \text { MPA, RPA \& LPA } & 1 & 3.1 \\ \quad \text { Non-confluent } & 31 & 96.9 \\ \quad \text { Confluent } & & \\ \text { Angle between MPA-LPA } & 17 & 53.1 \\ \quad \text { Acute } & 15 & 46.9 \\ \quad \text { obtuse } & 2 & 6.2 \\ \text { Acute angle between MPA-RPA } & & \\ \text { McGoon ratio } & 4 & 12.5 \\ \quad \text { Normal } & 28 & 87.5 \\ \text { Reduced } & & \\ \quad \text { If McGoon ratio reduced ( } \mathrm{n}=28) & 22 & 68.8 \\ \quad \text { Significant } & 6 & 18.8 \\ \quad \text { Not Significant } & \end{array}$

Table V. Distribution of patients by commonly associated anomalies $(n=32)$

$\begin{array}{lcc}\begin{array}{l}\text { Commonly associated } \\ \text { anomalies }\end{array} & \text { Frequency } & \text { Percentage } \\ \text { PDA } & 3 & 9.4 \\ \text { MAPCAs } & 30 & 93.8 \\ \text { ASD } & 4 & 12.5 \\ \text { Coronary Artery Anomalies } & 4 & 12.5 \\ \text { Aortic arch } & & \\ \quad \text { Right sided } & 3 & 9.4 \\ \quad \text { Left sided } & 29 & 90.6 \\ \text { Double SVC } & 1 & 3.1 \\ \text { IVC drains into RA } & 30 & 93.8\end{array}$

\begin{tabular}{lcc}
$\begin{array}{l}\text { Table VI. Distribution of patients by common associated } \\
\text { anomalies }(\mathbf{n}=\mathbf{3 2})\end{array}$ & Frequency & Percentage \\
\hline Less common anomalies & 1 & 3.1 \\
Persistent left superior vena cava & 3 & 9.4 \\
\hline Aberrant left subclavian artery &
\end{tabular}

\section{Discussion:}

The complex pulmonary artery anatomy and pulmonary atresia in patients with tetralogy of Fallot is easily defined by MDCT, along with the major aorto-pulmonary collateral vessels. ${ }^{14,15}$ Pulmonary atresia is the most severe form of 
antero-cephalad deviation of the outlet septum. However, in some occasions the pulmonary valve is affected solely by being completely imperforate, not just stenotic. ${ }^{3}$ In the present study, majority of the patients had levocardia $(93.8 \%)$, situs solitus $(96.9 \%)$ with none of the patients having either atrio-ventricular or arterio-ventricular discordance. Major findings of the patients were VSD (93.8\%), right ventricular outflow tract obstruction $(85 \%)$ with ventricular hypertrophy $(75 \%)$. All patients had overriding of aorta. Over $60 \%$ of the patients had $50 \%$ and $28 \%>50 \%$ overriding of aorta. Thirty-one (96.9\%) patients had main pulmonary artery (MPA) stenosis and $3.1 \%$ patients had main pulmonary artery (MPA) atresia. While MPA stenosis was detected in majority (96.9\%) of the cases, RPA and LPA stenoses were found in 50 and $60 \%$ of the cases respectively. Zakaria and colleagues ${ }^{16}$ in their study showed that $9 \%$ of pulmonary atresia involved the main trunk as well as its major branches. The rest of the cases were diagnosed by MDCT with different degrees of pulmonary artery stenosis. ${ }^{16}$ In patients with tetralogy-type pulmonary atresia, a diversity of systemic sources share in the pulmonary blood flow. ${ }^{17}$ In about 50\% of the patients with pulmonary atresia, there was confluence of the right and left pulmonary arteries, with persistently patent arterial duct giving blood to the pulmonary arteries. ${ }^{18}$ However, the present study demonstrated a higher incidence of confluence (96.9\%) of MPA, RPA and LPA. In cases with atretic pulmonary arteries, multiple collateral arteries give the blood supply to the lungs, or a combination of collateral arteries and an arterial duct are the source. ${ }^{3}$

Very few patients in the present study were diagnosed with PDA. Zakaria and colleagues ${ }^{16}$ demonstrated a significant presence $(48 \%)$ of PDAs in their study with MDCT clearly demonstrating their patency, extensions, length and diameter as well as their exact location. The assessment of sidedness in general (situs) should include cardiac, pulmonary, and abdominal sidedness, which are usually concordant. Cardiac sidedness is identified by the position of the morphologic right atrium and is different from cardiac position, cardiac orientation, and the positions of the ventricles or great arteries. However, in some rare cases of Fallot's Tetralogy there is associated situs inversus. In the present study only one case $(3 \%)$ was found so. All other cases were situs solitus. In situs solitus (the normal configuration), the morphologic right atrium lies to the right of the morphologic left atrium. In situs inversus, the morphologic right atrium lies to the left of the morphologic left atrium ${ }^{13}$.

In cases with overriding of the aorta, the aorta becomes more inclined to the right ventricle than to the left ventricle, leading in many cases to the ventriculo-arterial connection of double outlet right ventricle. ${ }^{3}$ In patients where the aorta originates mainly from the right ventricle there is a greater risk of developing obstruction of the left ventricular outflow tract. This tract is produced by a patch which closes the ventricular septal defect connecting the left ventricle to the aorta. In these cases, this patch is markedly longer than that seen when the aorta arises mostly from the left ventricle. ${ }^{3}$ In our study all cases had double outlet right ventricle. Zakaria ${ }^{16}$ found 2 out of 23 cases with double outlet right ventricle, one being associated with a right-sided aortic arch.

Two percent of patients with tetralogy of Fallot have an associated atrioventricular septal defect. ${ }^{3}$ However, in the current study, $12.5 \%$ of the patients were found with ASD which compares well with the findings of Zakaria et $\mathrm{al}^{16}$ who found $13 \%$ of the cases with ASD. The presentation and initial medical management of Tetralogy of Fallot patients with this association remain unchanged. However, surgical repair and post-operative care are more complex. ${ }^{3}$ Available literatures reported that $25-30 \%$ of patients with tetralogy of Fallot have an associated right aortic arch ${ }^{3,16}$ which causes no haemodynamic consequence. However, the present study observed a low incidence $(9.4 \%)$ of right-sided aortic arch.

Summarizing the findings of the study and discussion thereof, it is evident that MDCT clearly 
demonstrates information about the complex cardiovascular anatomy of Tetralogy of Fallot, which is supported by Khositseth et al. ${ }^{19}$ Its diagnostic accuracy in assessing the Tetralogy of Fallot patients' central and peripheral pulmonary arteries, aorto-pulmonary collateral vessels as well as in demarcating the abnormal venous anatomy \& veno-atrial connections is commendably high. It has already been demonstrated by several investigators. ${ }^{10}$ Moreover, it can be done safely and quickly even in small infants.

\section{Strengths and limitations:}

Easy availability, short scanning time and non-invasive vascular imaging are some of the advantages of MDCT. Accurate extracardiac arterial and venous vascular imaging is attainable by contrast-enhanced MDCT. However, there are still drawbacks of MDCT including patient exposure to ionizing radiation and the risks of iodinated contrast material. ${ }^{10}$ So, due stress must be put on radiation exposure issues, because the first CT examination in patients with tetralogy of Fallot usually applies in childhood or in early adulthood, and more often than not repeat scanning is needed. ECG-gated MDCT exposes the patient to a higher risk of radiation, so the benefits of evaluating the ventricular function, cardiac valves, small intracardiac abnormalities, and coronary arteries must outweigh these risks. The effective radiation dose from ECG-gated CT of the heart is estimated to be approximately 15 $\mathrm{mSv}$. For comparison, the effective radiation dose from non-gated CT of the chest is approximately 5 mSv. ${ }^{13}$ The second issue of contrast enhancement risks was partially resolved in the current study by the use of non-ionic contrast agent calculated according to the patient weight, with a maximum dose of $2 \mathrm{ml} / \mathrm{kg}$, injected at $1.2-2 \mathrm{ml} / \mathrm{s}$, thus reducing the risks of use of iodinated contrast material and the higher doses needed.

\section{CONCLUSION:}

MDCT examinations are essential when specific diagnostic questions are asked by the cardiologists, surgeons, \& radiologists after careful assessment of the clinical condition and other image findings.
This customized approach is an adjunct to clinical and other imaging findings and thus improves the diagnostic accuracy and reduces the unnecessary procedural prolongation \& sedation time. A careful preoperative evaluation of the complex cardiovascular anatomy in patients with Tetralogy of Fallot aids the cardiac surgeons in deciding their surgical approach.

\section{REFERENCES:}

1. Fallot ELA. Contribution a I'anatomie pathologique de la maladie bleu (cyanose cardiaque). Marseille Med 1888: 77-93.

2. Becker $A E$, Connor M, Anderson RH. Tetralogy of Fallot: a morphometric and geometric study. Am J Cardiol $1975 ; 35: 402-412$

3. Bailliard F, Anderson RH . Tetralogy of Fallot. Orphanet J Rare Dis 2009;4:2.

4. Ferguson EC, Krishnamurthy R, Oldham SAA. Classic imaging signs of congenital cardiovascular abnormalities. Radio Graphics 2007;27:1323-334.

5. Boechat MI, Ratib O, Williams PL, et al. Cardiac MR imaging and MR angiography for assessment of complex tetralogy of Fallot and pulmonary atresia. Radio Graphics 2005;25:1535-546.

6. Dabizzi RP, Teodori G, Barletta GA, et al. Associated coronary and cardiac anomalies in the tetralogy of Fallot: an angiographic study. Eur Heart J 1990;11: 692-704.

7. Brickner ME, Hillis LD, Lange RA. Congenital heart disease in adults-second of two parts. NEJM 2000; 342(5):334-342.

8. Groh MA, Meliones JN, Bove EL, et al. Repair of tetralogy of Fallot in infancy: effect of pulmonary artery size on outcome. Circulation 1991;84(Suppl.5):III206-III-212

9. Touati GD, Vouhe PR, Amodeo A, et al. Primary repair of tetralogy of Fallot in infancy. J Thorac Cardiovasc Surg 1990;99:396-402.

10. Haramati LB, Glickstein JS, Issenberg $\mathrm{HJ}$, et al. MR imaging and $\mathrm{CT}$ of vascular anomalies and connections in patients with congenital heart disease: significance in surgical planning. Radio Graphics 2002;22:337-349.

11. Flohr T, Stierstorfer K, Raupach R, et al. Performance evaluation of a 64-slice CT system with z-flying focal spot. Rofo $2004 ; 176: 803-810$.

12. Manghat NE, Morgan-Hughes GJ, Marshall AJ, et al. Multidetector row computed tomography: imaging congenital coronary artery anomalies in adults. Heart 2005; $91: 1515-522$.

13. Leschka S, Oechslin E, Husmann L, et al. Pre- and postoperative evaluation of congenital heart disease in children and adults with 64-section CT. Radio Graphics 2007;27:829-846. 
14. Westra SJ, Hill JA, Alegjos JC, Galindo A, Boechat MI, Laks $\mathrm{H}$. Three-dimensional helical CT of pulmonary arteries in infants and children with congenital heart disease. AJR Am J Roentgenol 1999;173:109-115.

15. Luciani GB, Wells WJ, Khong A, Starnes VA. The clamshell incision for bilateral pulmonary artery reconstruction in tetralogy of Fallot with pulmonary atresia J. Thorac Cardiovasc Surg 1997;113:443-452.

16. Zakaria RH, Barsoum NR, Asaad RE, El-Basmy AA, Azab AO. Tetralogy of Fallot: Imaging of common and uncommon associations by multidetector CT. The Egyptian Journal of Radiology and Nuclear Medicine $2011 ; 42(3-4): 289-95$
17. Mawson JB. Congenital heart defects and coronary anatomy. Tex Heart Inst J 2002;29(4):279-289.

18. Tetralogy of Fallot and Pulmonary Atresia. Pediheart Website<http://www. pediheart.org/practitioners/ defects/ventriculoarterial/TOF PA.htm >.Published February 14, 2004. [accessed 20.03.10].

19. Khositseth A, Pornkul R, Siripornpitak S. Diagnosis of tetralogy of Fallot with anatomically corrected malposition of the great arteries and single coronary artery by multidetector CT. Br J Radiol 2006;79:e5-e7. 